\title{
Penetrating trauma in children and adolescents in Pietermaritzburg
}

TRAUMA

\author{
L Khumalo-Mugabi, ${ }^{1}$ (D) S Moffatt, ${ }^{2}$ (D) W Bekker, ${ }^{3}$ (D) M Smith, ${ }^{3}$ (D) JL Bruce, ${ }^{3}$ (D) G Laing, ${ }^{3}$ (D) V Manchev, ${ }^{3}$ (D) \\ V Kong, ${ }^{4}$ DL Clarke ${ }^{3,4}$ iD
}

${ }^{1}$ Department of Paediatric Surgery, University of KwaZulu-Natal, South Africa

${ }^{2}$ University Hospitals Coventry and Warwickshire NHS Trust, United Kingdon

${ }^{3}$ Department of Surgery, Grey's hospital, Pietermaritzburg, University of KwaZulu-Natal, South Africa

${ }^{4}$ Department of Surgery, University of the Witwatersrand, South Africa

Corresponding author, email: nirusha.maharaj@kznhealth.gov.za

Background: This project aims to review the spectrum and outcome of penetrating trauma in children and adolescents with the objective of defining the extent of the problem and of developing strategies to reduce the incidence and severity of this form of trauma.

Methods: All patients less than eighteen years of age who were admitted to the Pietermaritzburg Metropolitan Trauma Service (PMTS) following penetrating trauma between December 2012 and December 2018 were identified from the Hybrid Electronic Medical Registry (HEMR).

Results: During the five-year period under review, a total of 164 patients less than eighteen years of age sustained penetrating trauma and were admitted to the PMTS. There were 138 males and 26 females. The mean age was 13.29 years and the median age 15 years. There were 70 stab wounds (SW) and 73 gunshot wounds (GSW). There were 21 non-intentional impalement injuries. The mean ISS was 9.04 and the median was 9 . A total of 155 plain X-rays were performed, $50 \mathrm{CT}$ scans and $51 \mathrm{CT}$ angiograms in this cohort of patients. Only two ultrasound examinations were performed. A total of 76 patients required an operation, which included 50 laparotomies. Of the patients who underwent a laparotomy, 18 required a repeat laparotomy. There were 46 other procedures undertaken in this cohort of patients, which included two thoracotomies, three laparoscopies and two thoracotomies. The median hospital stay was 2 days and 17 (10\%) patients required ICU admission and 7 (4\%) died.

Conclusion: Penetrating trauma in children and adolescents is associated with significant mortality and morbidity. There are similarities with the management of these injuries in adults, but further work is required to ensure that paediatric management algorithms are evidence based.

Keywords: children, vulnerable group, penetrating trauma, endemic, prevention

\section{Background}

South Africa remains plagued by an inordinately high level of trauma even after a quarter of a century of democracy. ${ }^{1-4}$ The reasons for this stubbornly high level are unclear and require further study. Whilst the spectrum of the epidemic has been assiduously documented by a number of authors, there remain cohorts of patients who have tended to be overlooked in the extensive trauma literature which has emanated from South African trauma centres over the last fifty years. This is a significant oversight as many of these cohorts of patients belong to well defined groups, who suffer a degree of double jeopardy in the sense that they are already vulnerable and relatively marginalised within broader society. These groups include women, children, the elderly, mental healthcare users and immigrants. This project aims to address this deficit by focusing on trauma in a vulnerable group, namely children and adolescents. ${ }^{1-4}$ It focuses on a specific mechanism of trauma which is generally less common in this group, namely penetrating trauma. Trauma can be divided into mechanisms and intentions. This is important when developing trauma and injury prevention programmes. Blunt trauma is usually unintentional in nature and can be targeted directly by prevention programmes which are mechanical in nature, such as improved safety features in vehicles and traffic calming speed bumps. Penetrating trauma is usually intentional in nature and this makes it challenging to prevent as prevention programmes need to target perpetrators' behaviour, and this is far more difficult to achieve. ${ }^{1-4}$ This project therefore aims to review the spectrum and outcome of penetrating trauma in children and adolescents, with the objective of defining the extent of the problem and of developing strategies to reduce the incidence and severity of this form of trauma.

\section{Clinical setting}

The Pietermaritzburg Metropolitan Trauma Service (PMTS) is based in the city of Pietermaritzburg, South Africa. It provides trauma care to the city of Pietermaritzburg with its population of one million people and tertiary trauma care to the predominantly rural western third of the province of KwaZulu-Natal. This is a large geographical area serviced by 19 district hospitals and two regional hospitals, with a 
population of two million people. The PMTS maintains a digital database called the Hybrid Electronic Medical Registry (HEMR) which captures data on all admissions to the service.

\section{Methods}

All patients less than eighteen years of age who were admitted to the PMTS following penetrating trauma between December 2012 and December 2018 were identified from the HEMR. Basic demographic data was documented along with the mechanism and the severity of the injury. All injured body cavities and organs were documented and graded. The management strategies were documented, and the outcomes recorded. Basic statistics were performed using Excel.

\section{Results}

During the five-year period under review, a total of 8722 trauma patients were admitted to Grey's Hospital. There were $7442(83 \%)$ males. The average age was 29.66 years. A total of $1719(20 \%)$ patients 18 years of age or less, 377 $(45 \%)$ older than 60 years and $1480(16 \%)$ female patients were admitted following trauma. During this period, a total of 164 patients less than eighteen years of age sustained penetrating trauma and were admitted. This is just under $10 \%$ of all paediatric trauma. There were 138 males and 26 females. The mean age was 13.29 years and the median age 15 years. There were 70 stab wounds (SW) and 73 gunshot wounds (GSW). There were 21 non-intentional impalement injuries. The breakdown of the various weapons used is provided in Table 1. The presenting physiology is shown in Table 2. The mean ISS was 9.04 and the median was 9. A total of 155 plain X-rays, $50 \mathrm{CT}$ scans and 51 CT angiograms were performed in this cohort of patients.

\section{Table 1: Mechanism}

\begin{tabular}{lc} 
Table 1: Mechanism & $(\boldsymbol{n}=\mathbf{7 0})$ \\
\hline Knife & 47 \\
Bottle & 3 \\
Spear & 2 \\
Screwdriver & 1 \\
Sharp metal & 1 \\
Axe & 1 \\
Wooden rod & 1 \\
Unknown weapon & 14 \\
Gunshot & $(\boldsymbol{n}=\mathbf{7 3 )}$ \\
\hline High velocity & 6 \\
Low velocity & 42 \\
Shotgun & 1 \\
Air gun/pellet gun & 8 \\
Unknown weapon & 16 \\
Impalement & $(\boldsymbol{n}=\mathbf{2 1 )}$ \\
\hline Metal rod & 8 \\
Knife & 2 \\
Glass & 2 \\
Tree branch & 2 \\
Bicycle & 1 \\
Bottle & 1 \\
Nail & 1 \\
Corrugated iron sheeting & 3 \\
Unknown weapon & 1 \\
&
\end{tabular}

Only two ultrasound examinations were performed. Table 3 provides a breakdown of the body regions injured. A total of 76 patients required an operation, which included 50 laparotomies. Of the patients who underwent a laparotomy, 18 required a repeat laparotomy. Tables $4 \mathrm{~A}$ and $4 \mathrm{~B}$, tabulate the laparotomy findings and the findings at repeat laparotomy. There were 46 other procedures undertaken in this cohort of patients which included two

\begin{tabular}{lc} 
Table 2: Physiology & \\
\hline Mean HR (BPM) & 98.28 \\
HR range (BPM) & $17-195$ \\
Median HR $(\mathrm{BPM})$ & 94.5 \\
Mean SBP $(\mathrm{mmHg})$ & 116.58 \\
SBP range $(\mathrm{mmHg})$ & $66-173$ \\
Median SBP $(\mathrm{mmHg})$ & 118 \\
Mean lactate $(\mathrm{mmol} / \mathrm{L})$ & 2.11 \\
Lactate range $(\mathrm{mmol} / \mathrm{L})$ & $0.4-12.4$ \\
Median lactate $(\mathrm{mmol} / \mathrm{L})$ & 1.4
\end{tabular}

Table 3: Injury location

Head, neck and face

65

Chest 44

Abdomen and pelvis 71

Urogenital

Upper limb 20

Lower limb 24

Table 4A: Laparotomy findings

\begin{tabular}{lc}
\hline Laparotomy & $(\boldsymbol{n}=\mathbf{5 0})$ \\
\hline No visceral injury found & 6 \\
Small bowel anastomosis & 5 \\
Small bowel resection & 7 \\
Small bowel repair & 14 \\
Large bowel repair & 9 \\
Gastric repair & 7 \\
Bladder repair & 2 \\
Vascular ligation & 3 \\
Vascular repair & 2 \\
Stoma formation & 9 \\
Hemicolectomy & 2 \\
Repair of abdominal wall or sheath defect & 2 \\
Liver packing & 3 \\
Lavage & 4 \\
Appendicectomy & 2 \\
Abdominal packing & 1 \\
Diaphragmatic repair & 1 \\
Nephrectomy & 1 \\
Ladd's procedure & 1 \\
Esophagectomy & 1 \\
Jejunostomy & 1 \\
Gastrostomy & 1
\end{tabular}


Table 4B: Repeat laparotomy

\begin{tabular}{lc}
\hline Repeat laparotomy & $(\boldsymbol{n}=\mathbf{1 8})$ \\
\hline Colostomy closure & 1 \\
Bowel anastomosis & 1 \\
Liver suture & 2 \\
Lavage & 10 \\
Stoma formation & 1 \\
Duodenojejunostomy & 1 \\
Small bowel repair & 1 \\
Vascular graft & 1 \\
Adhesiolysis & 2 \\
Bowel decompression & 1 \\
Mesenteric defect repair & 1 \\
Hemicolectomy & 1 \\
Small bowel resection & 1 \\
Small bowel anastomosis & 1
\end{tabular}

Table 5: Extra-abdominal procedures

\begin{tabular}{ll}
\hline Extra-abdominal procedures & $(\boldsymbol{n}=\mathbf{4 6})$ \\
\hline Thoracotomy for esophagectomy & 1 \\
Thoracotomy for ventricular repair & 1 \\
Laparoscopy & 3 \\
Thoracoscopy for diaphragmatic repair & 2 \\
Sigmoidoscopy & 3 \\
Wound exploration & 6 \\
Wound debridement & 6 \\
Split skin graft & 1 \\
Vascular repair & 2 \\
Vascular ligation & 5 \\
Craniotomy/craniectomy/burr hole & 3 \\
Neurosurgical debridement & 1 \\
Embolisation of traumatic AV fistula & 1 \\
Femoral nail & 1 \\
Amputation of toe & 1 \\
Esophageal repair & 1 \\
Pharyngeal repair & 1 \\
Thyroid cartilage approximation & 1 \\
Urological surgery & 1 \\
Removal of retained weapon (knife) & 1 \\
Excision of eviscerated omentum & 2 \\
Eyelet wiring for mandible fracture & 1 \\
Tracheostomy & 1 \\
\hline
\end{tabular}

thoracotomies, three laparoscopies and two thoracoscopies. These other procedures are tabulated in Table 5. The median hospital stay was 2 days, 17 (10\%) patients required ICU admission and 7 (4\%) died.

\section{Discussion}

Trauma is a global health problem and remains the biggest single cause of death in patients less than forty years of age. A comprehensive strategy to deal with this burden is necessary. Such a program needs to emphasise preventative strategies as well as curative and rehabilitative ones. To develop preventative strategies, a good understanding of the epidemiology and demographics of the problem is necessary. It is clear that there are different sub-populations of trauma patients and these cohorts are distinct in their spectrum of trauma and risk. One such cohort is children and adolescents, yet there have been few reports from South Africa examining paediatric trauma in detail. ${ }^{1-4}$ It is apparent from the international literature that most paediatric trauma is blunt and is secondary to an accident. ${ }^{5-8}$ This type of trauma lends itself to mechanical prevention strategies like mandating the wearing of seat belts in cars, outlawing the transportation of children in the back of flat-bed trucks and the placement of traffic calming speed humps near schools. Penetrating trauma, however, is almost always intentional in nature, and this makes it more difficult to develop prevention strategies as it is the behaviour of the perpetrator that needs to be altered. This situation has been reported from other countries. $^{5-10}$

It would appear that there are consistent risk factors for children and adolescents to sustain penetrating trauma. Heavily racialised and divided societies with high levels of endemic poverty seem to be most prone to experiencing paediatric penetrating trauma. The risk factors for paediatric penetrating trauma as reported from the United States includes race and socio-economic status, with being a young male and member of either the African American or Hispanic ethnic group being closely associated with the risk of sustaining penetrating trauma. ${ }^{5-10}$ This has been commented on by a number of authors. Between 2000 and 2009 the three trauma centres in San Francisco saw a total of 598 patients who were sixteen years or younger, with penetrating trauma. There were 432 gunshot wounds (GSWs), 141 stabbings, and 25 other mechanisms. The mean age of the patients was $13.8(0.1)$ years. African Americans and Hispanics sustained $82.5 \%$ of penetrating trauma and there was a strong correlation between deprivation indices and the addresses of the victims. The overall mortality rate was $9.2 \%$. There has been a steady increase in penetrating paediatric trauma in the USA over the last five decades. ${ }^{5-10}$ The absolute number of children with penetrating trauma in Harlem Hospital Centre increased from single figures in the 1960 s to 108 during the $1970 \mathrm{~s}^{5-7}$ This rise correlated with the spread of the illicit narcotic trade in the area. In the 1980s, authors began to refer to interpersonal violence involving children and adolescents in Los Angeles and Chicago as an epidemic. Between 1988 and 1993 at Chicago's Cook County Hospital, the incidence of penetrating trauma in all patients younger than 16 years rose from $20 \%$ to $36 \%$ and rose from $45 \%$ to $66 \%$ in children aged 12 years to 15 years. ${ }^{5-7}$ Researchers estimated that across the United States there were 14831 emergency department visits by children and adolescents following a firearm related injury in 2008, and that there were a total of 817 fatalities amongst them following a GSW. These increases, however, are confined to specific geographical regions and demographic groups and are not in keeping with broad national trends. The Centre for Disease Control and Prevention reported that between 1993 and 2000 the nation-wide incidence of gunshot wounds and fatalities declined dramatically by more than half. ${ }^{5-10}$

The situation is similar in countries in western Europe which are experiencing an emergence of a trauma epidemic 
secondary to penetrating injury. The United Kingdom has seen a dramatic spike in penetrating trauma in major cities with large racialised and economically deprived social groupings. The rise in knife crime in London has been well described in the press and has become a political debating point. ${ }^{11-13}$ What is apparent is that the certain boroughs in London bear the brunt of this burden. There is a real risk that in certain communities violence can become endemic and almost impossible to counter. This is a major problem in South Africa, where the trauma epidemic shows little signs of abating and the high rate of interpersonal and intentional trauma remains cause for concern.

Other South African centres also report a high incidence of firearm injuries in children and adolescents. One hundred and sixty-three children presented with firearm injuries to the Red Cross War Memorial Hospital between 2001 to 2010. The mortality rate was to $2.6 \% .^{3}$ However, this is an underestimation of the problem as the age cut-off used was 12 years of age and this excludes adolescents. A more recent publication from the trauma unit at Groote Schuur Hospital reports that over the 33-month period (April 2014 to December 2016) 2889 adolescents were seen at the trauma centre and that $1380(48 \%)$ had an intentional injury of which 946 sustained a penetrating injury. ${ }^{4}$ These were almost evenly divided between stab wounds 428 (45\%) and gunshot wounds $358(38 \%)$. The mortality rate was $2 \%$. The authors ascribed this huge burden to the ongoing pandemic of gang related activity and illicit drug trade in the Western Cape.

Although the management of trauma in children and adolescents follows the same principles as the management of adult trauma, it is important to remember that there are nuances. This vulnerable cohort deserves more focused attention to validate management strategies, which have mostly been refined in adult populations. ${ }^{15,16}$

\section{Conclusion}

As is the situation in other countries with racialised and economically segregated communities, like the USA and United Kingdom, penetrating trauma in children and adolescents remains a major problem and is associated with significant mortality and morbidity. There are similarities with the management of these injuries in adults but further work is required to ensure that paediatric management algorithms are evidence based.

\section{Conflict of interest}

The authors have no conflicts of interest to declare.

No external or internal funding was utilised to generate this work.

\section{Ethics approval}

Ethics approval for the maintenance of our registry and for this study was formally approved by the Biomedical Research Ethics Committee of the University of KwaZuluNatal (Reference number: BCA 207/09 and BCA 221/13).

\section{ORCID}

L Khumalo-Mugabi (D) http://orcid.org/0000-0003-2420-123X S Moffatt (iD http://orcid.org/0000-0002-7649-4970

W Bekker (iD http://orcid.org/0000-0003-0695-5994

M Smith (iD http://orcid.org/0000-0003-1491-0534

JL Bruce (iD http://orcid.org/0000-0001-8666-4104
G Laing (iD) http://orcid.org/0000-0001-8075-0386

V Manchev (iD http://orcid.org/0000-0001-9152-0092

DL Clarke (i) http://orcid.org/0000-0002-6954-153X

\section{REFERENCES}

1. Manchev V, Bruce JL, Oosthuizen GV, Laing GL, Clarke DL. The spectrum of paediatric and adolescent trauma managed by the Pietermaritzburg Metropolitan Trauma Service. Ann R Coll Surg Engl. 2015 May;97(4):274-8. doi: 10.1308/003588 414X14055925061595. PMID: 262639341.22.

2. Tadema-Meijering VM, Navsaria PH, Nicol A, et al. Spectrum of intentional injuries in the adolescent population treated at a South African level one trauma centre. Glob Surg. 2018;4(3):2-4 doi: 10.15761/GOS.1000185.

3. Hadley GP, Mars M. Gunshot injuries in infants and children in KwaZulu-Natal--an emerging epidemic? S Afr Med J. 1998 Apr;88(4):444-7.

4. Campbell NM, Colville JG, Van der Heyde Y, Van As AB. Firearm injuries to children in Cape Town, South Africa: impact of the 2004 Firearms Control Act. S Afr J Surg. 2013 Jul 31;51(3):92-6. doi: 10.7196/sajs. 1220.

5. Barry WE, Barin E, McLaughlin CM, et al. Pediatric firearm injuries in Los Angeles County: Younger children are more likely to be the victims of unintentional firearm injury. J Pediatr Surg. 2019 Feb;54(2):350-3. pii: S0022-3468(18)30680-8. doi: 10.1016/j.jpedsurg.2018.10.050. Epub 2018 Oct 22.

6. Schecter SC, Betts J, Schecter WP, Victorino GP. Pediatric penetrating trauma: the epidemic continues. J Trauma Acute Care Surg. 2012 Sep;73(3):721-5. doi: 10.1097/ TA.0b013e318265cdce.

7. Barlow B, Niemirska M, Gandhi RP. Ten years' experience with pediatric gunshot wounds. J Pediatr Surg. 1982;17:927Y932.

8. Howell J. Youth Gang Drug Trafficking and Homicide: Policy and Program Implications. Available from: http:/www.ojjdp. gov/jjjournal/jjjournal1297/gang.html. Accessed 14 Dec 2018.

9. Nance ML, Sing RF, Reilly PM, Templeton JM Jr, Schwab CW. Thoracic gunshot wounds in children under 17 years of age. J Pediatr Surg. 1996 Jul;31(7):931-5.

10. Nance ML, Stafford PW, Schwab CW. Firearm injury among urban youth during the last decade: an escalation in violence. J Pediatr Surg. 1997 Jul;32(7):949-52.

11. Nance ML, Templeton JM Jr, O’Neill JA Jr. Socioeconomic impact of gunshot wounds in an urban pediatric population. $\mathrm{J}$ Pediatr Surg. 1994 Jan;29(1):39-43.

12. Shaw D. Ten charts on the rise of knife crime in England and Wales. BBC News. 2019 July 18. Available from https://www. bbc.com/news/uk-42749089.

13. Press Association. Jay Hughes stabbing: teenager charged with murder. The Guardian. 2018 Dec 12. Available from https:/www.theguardian.com/uk-news/2018/dec/12/jayhughes-stabbing-teenager-charged-with.

14. Siddique H. Coventry stabbing: boy was killed because of his postcode, says sister. The Guardian. 2018 Nov 26. Available from https://www.theguardian.com/uk-news/2018/nov/26/ coventry-stabbing-boy-was-killed-because-of-his-postcodesays-sister.

15. Eren S, Balci AE, Ulku R, Cakir O, Eren MN. Thoracic firearm injuries in children: management and analysis of prognostic factors. Eur J Cardiothorac Surg. 2003 Jun;23(6):888-93.

16. Dokucu AI, Otçu S, Oztürk $\mathrm{H}$, et al. Characteristics of penetrating abdominal firearm injuries in children. Eur $\mathrm{J}$ Pediatr Surg. 2000 Aug;10(4):242-7. 